\title{
DISTRIBUIÇÃO DIFERENCIAL DE PALINOMORFOS NA BAÍA DE GUANABARA, RIO DE JANEIRO, BRASIL
}

\author{
CINTIA FERREIRA BARRETO \\ Departamento de Geologia e Curso de Pós-Graduação em Paleontologia e Estratigrafia, UFRJ, IGEO, Ilha do Fundão, \\ 21949-900, Rio de Janeiro, Brasil.cintiapalino@yahoo.com.br \\ ORTRUD MONIKA BARTH \\ Departamento de Botânica, UFRJ, Ilha do Fundão, 21949-900, Rio de Janeiro, Brasil. \\ Instituto Oswaldo Cruz, Av. Brasil 4365, 21040-900 Rio de Janeiro, RJ, Brasil. barth@ioc.fiocruz.br
}

CYNTHIA FERNANDES PINTO DA LUZ

Departamento de Geologia e Departamento de Botânica, UFRJ, Ilha do Fundão, 21.949-900, Rio de Janeiro, Brasil.

\section{LUCIANE GUIMARÃES COELHO}

Departamento de Ecologia, UFRJ, Ilha do Fundão, 21.949-900, Rio de Janeiro, Brasil. Rio de Janeiro, Brasil.

CLAUDIA GUTTERRES VILELA

Departamento de Geologia, UFRJ, IGEO, Ilha do Fundão, 21.949-900 Rio de Janeiro, Brasil.

\begin{abstract}
RESUMO - O presente trabalho tem como objetivo caracterizar os processos de sedimentação atual que controlam a deposição de palinomorfos em vários setores da baía de Guanabara, Rio de Janeiro. Foram coletadas 27 amostras de sedimentos superficiais dentro da baía e tratadas pelo método palinológico por peneiramento e, em seguida, pelo método padronizado para sedimentos quaternários. Os resultados obtidos apresentaram um percentual maior de tipos polínicos relacionados à vegetação campestre e uma grande riqueza de tipos polínicos da floresta ombrófila/mata atlântica. A distribuição diferencial dos palinomorfos seguiu um padrão influenciado pela batimetria, associado ao padrão de correntes gerado pelas marés, os quais promoveram a maior concentração dos palinomorfos nas áreas mais profundas e em locais de obstrução topográfica. A deposição diferencial, em relação ao tamanho dos palinomorfos, seguiu um padrão de acúmulo de palinomorfos de tamanho pequeno nas áreas de maior energia dos fluxos aquáticos e os de tamanho grande em áreas de águas mais calmas, lateralmente à desembocadura dos rios.
\end{abstract}

Palavras-chave: Palinologia, Quaternário, baía de Guanabara, palinomorfos.

ABSTRACT - DIFFERENTIAL DISTRIBUTION OF PALYNOMORPHS IN THE GUANABARA BAY, RIO DE JANEIRO, BRAZIL. The present paper aims to characterize the modern depositional processes that control the palynomorph accumulation in several sectors of the Guanabara Bay. A total of 27 samples of surface sediments obtained inside the Guanabara Bay were collected and treated using palynological sieving methodology followed by the standard chemical treatment for Quarternary sediments. The results obtained showed a high percentual of fields ("Vegetação Campestre") elements and a high richness of pollen grains from the mixed rainforest ("Floresta Ombrófila"). The differential distribution of palynomorphs followed a pattern that was influentiated by the bathymetry associated to the guidance of tide currents, which originated the highest concentration of palynomorphs in the deeper and topographical obstructed areas. The differential deposition in relation to the size of palynomorphs followed a model of accumulation of small palynomorphs inside the areas of high energy of the aquatic flow, and large size palynomorphs in quiet water areas and laterally to the discharge of the rivers.

Key words: Palynolology, Quaternary, Guanabara Bay, palynomorphs. 


\section{INTRODUÇÃO}

A distribuição e o acúmulo de palinomorfos em uma baía são influenciados pelas distintas situações de batimetria, velocidade de corrente de maré e intensidade dos influxos fluviais. Para Traverse (1994), a relação entre a circulação das águas e o padrão de sedimentação existente em uma baía afeta diretamente a acumulação de palinomorfos.

A deposição diferencial dos palinomorfos é afetada, em bacias lacustres, pela circulação interna das águas que promove a sedimentação polínica, de acordo com os tamanhos e a densidade dos palinomorfos. De maneira geral, os grãos de pólen que apresentam taxas de submersão lenta na água sugerem possuir tamanho reduzido ou uma baixa densidade; assim, permanecem em suspensão nas águas turbulentas por mais tempo, sendo carreados pelos ventos e por correntes, depositando-se mais próximo ao litoral (Davis \& Brubaker, 1973). Em estudos realizados na região norte do Estado do Rio de Janeiro, Toledo (1998) verificou que, em uma lagoa sem afluentes e efluentes, a deposição de palinomorfos é influenciada pela batimetria. Já para Luz (2003), estudando uma lagoa com afluentes, os influxos fluviais, a ação do vento e a batimetria têm grande influência na sedimentação diferencial espacial de grãos de pólen, dos esporos e das algas, e depende também do tamanho dos palinomorfos.

Dados provenientes de pesquisas sistemáticas desenvolvidas na baía de Guanabara e em sua bacia hidrográfica nas últimas décadas, principalmente por Amador (1997), têm fornecido informações sobre sua evolução ambiental e seu complexo sistema hidrodinâmico. Estudos paleoecológicos, baseados na Palinologia, desenvolvidos por Barreto et al. (2003) e Barth et al. (2004), têm fornecido esclarecimentos sobre as mudanças na cobertura vegetal da região nos últimos 4.000 anos.

A fim de poder interpretar melhor a vegetação do passado, é necessário compreender os processos que controlam a deposição atual dos palinomorfos. O presente trabalho tem como objetivo caracterizar os processos da dinâmica atual que controlam a deposição de palinomorfos nos vários setores da baía de Guanabara, favorecendo a indicação das melhores áreas para a realização de estudos palinológicos futuros nessa baía.

\section{ASPECTOS GERAIS DA ÁREA DE ESTUDO}

A baía de Guanabara está localizada no litoral do Estado do Rio de Janeiro $\left(22^{\circ} 40^{\prime \prime}\right.$ e $23^{\circ} 00^{\prime \prime} \mathrm{S} / 43^{\circ} 00^{\prime \prime}$ e $\left.43^{\circ} 20^{\prime \prime} \mathrm{W}\right)$, entre as cidades do Rio de Janeiro e de Niterói (Figura 1). Ela representa um importante ecossistema que tem resistido à ação depredatória pelo homem, iniciada no ano de 1500 e drasticamente acentuada nas últimas décadas.

A baía de Guanabara encontra-se sob a influência de um clima quente e úmido. As temperaturas médias anuais são de $23,7^{\circ} \mathrm{C}$ e as médias de umidade relativa do ar são de $78 \%$, com a precipitação fluvial total anual média superior a $2.000 \mathrm{~mm}$ no topo da Serra do Mar e oscilando entre 1.000 e $1.500 \mathrm{~mm}$ na Baixada Fluminense (Amador, 1997). A estação chuvosa é bem definida entre dezembro e abril e, a outra, de seca, entre junho e agosto (Kjerfve et al., 1997).

O tipo de vegetação remanescente, na região da baia de Guanabara é representado pela Floresta Ombrófila Densa (domínio de Mata Atlântica), atualmente localizada em topografia acidentada (encostas das serras), principalmente, e em reservas florestais (Radambrasil, 1983; Veloso et al., 1991; Kurtz \& Araújo, 2000). Cabe destacar que as áreas de vegetação de mangue, em 1500, abrangiam quase a totalidade de sua orla. Atualmente, estão limitadas a uma grande mancha contínua no litoral dos municípios de Magé, Itaboraí, São Gonçalo e a ocorrências esparsas no litoral de Duque de Caxias e na Ilha do Governador (Amador, 1997).

A baía de Guanabara apresenta uma entrada estreita, de aproximadamente 1,6 km de largura, que se amplia no sentido S-N até o seu fundo, alcançando uma extensão máxima de 28 $\mathrm{km}$, com um perímetro de $131 \mathrm{~km}$. A superfície do espelho d'água mede atualmente $373 \mathrm{~km}^{2}$, excluindo as suas ilhas e considerando somente seus limites externos. Sua bacia hidrográfica abrange aproximadamente $4.600 \mathrm{~km}^{2}$, englobando quase toda a região metropolitana das cidades do Rio de Janeiro, de Niterói e de São Gonçalo, entre outras. São em torno de 35 os rios que desembocam na baía, sendo que os maiores (rios Macacu e Caceribu) nascem na Serra do Mar (Amador, 1997).

Segundo Quaresma (1997), na estreita barra de entrada da baía de Guanabara, existe um grande banco arenoso, localizado nas coordenadas $22^{\circ} 56^{\prime} 48^{\prime \prime} \mathrm{S} / 43^{\circ} 07^{\prime} 54^{\prime \prime} \mathrm{W}$, que se eleva desde a profundidade de $20 \mathrm{~m}$ até $11 \mathrm{~m}$. Esta feição promove a canalização das correntes e funciona como um obstáculo à livre circulação das correntes de maré. $\mathrm{Na}$ topografia de fundo da baía, uma feição que merece destaque é o canal central, de orientação geral N-S, seguindo desde a entrada da barra até próximo à Ilha do Governador. As profundidades mais comuns deste canal estão em torno de $30 \mathrm{e}$ $40 \mathrm{~m}$, sendo que, próximo à Ilha Laje, existe uma depressão que chega a atingir $58 \mathrm{~m}$ de profundidade (Dias \& Quaresma, 1996).

As marés da baía de Guanabara são classificadas como semidiurnas, com um período de cerca de $12,5 \mathrm{~h}$, apresentando diferenças nas alturas da preamar e baixa-mar, cujas amplitudes variam de $1,40 \mathrm{~m}$ a $20 \mathrm{~cm}$ e com amplitude média de sizígia cerca de 1,20 m (Amador, 1997). As oscilações de marés observadas na área originam-se devido à sua conexão com o Oceano Atlântico, repercutindo em oscilações no interior da baía. A propagação da onda de maré para seu interior sofre alterações de fase e de amplitude em função da geometria da baía de Guanabara.

\section{MATERIAIS E MÉTODOS}

Entre novembro de 1999 e junho de 2000, foram coletadas 27 amostras de sedimentos superficiais, utilizando-se o amostrador de fundo do tipo "Van-Veen". As coordenadas dos pontos de coleta foram obtidas por GPS. A amostragem foi iniciada na barra de entrada da baía, seguindo-se em direção ao interior, no sentido N (Figura 1). 


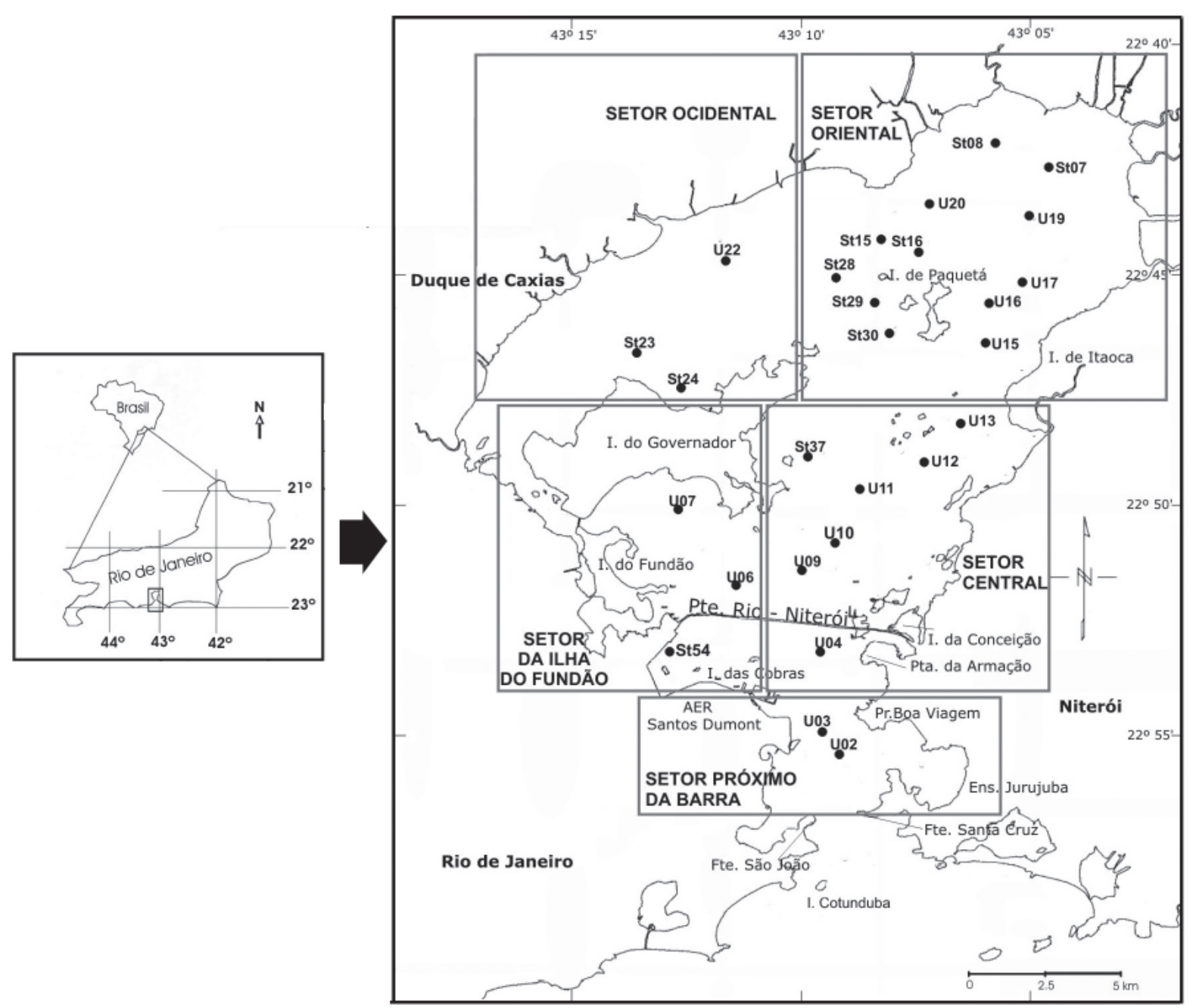

Figura 1. Mapa de localização das amostras de sedimentos superficiais nos diferentes setores da baía de Guanabara (Vilela et al., 2002). Figure 1. Map of surface sediment samples location inside the sectors established in the Guanabara Bay (Vilela et al., 2002).

As amostras localizadas entre a barra de entrada e, aproximadamente, $4 \mathrm{~km}$ após a ponte Rio-Niterói constituemse de areias, que variaram desde areia média até areia muito fina, pobre a moderadamente bem selecionadas, seguindo a direção ao interior da baía no sentido N. A partir do alinhamento Forte do Gragoatá e Aeroporto Santos Dumont, as amostras apresentaram sedimentos mais finos como argilas siltosas e siltes argilosos. Nas amostras localizadas na região mais interna da baía (após a Ilha do Governador - NW), observou-se a predominância de argilas-siltosas. Em contrapartida, as amostras localizadas na parte mais a NE da baía apresentaram uma sedimentação mais lamosa, com predominância de argilas (Catanzaro, 2002).

A preparação das 27 amostras de sedimentos superficiais foi realizada em duas etapas subseqüentes: o método palinológico por peneiramento descrito por Brenner (1998), e o método padronizado para sedimentos quaternários descrito por Ybert et al. (1992), com modificações. Para obter dados de concentração absoluta de palinomorfos por volume de sedimento foram introduzidas duas pastilhas de Lycopodium clavatum a cada amostra (Stockmarr, 1971). Foi estabelecida a contagem de um mínimo de 150 grãos de pólen por amostra, observando-se cinco lâminas. Para a identificação dos palinomorfos foi utilizada a literatura disponível (Veloso \& Barth, 1962; Barth, 1962a, 1962b, 1963, 1964, 1971a, 1971b, 1972a, 1972b, 1975, 1976a, 1976b; Barth \& Silva, 1963, 1965; Barth \& Bouzada, 1964; Barth \& Yoneshigue, 1966; Barth \& Barbosa, 1971, 1972a, 1972b, 1972c, 1973, 1975a, 1975b, 1976a, 1976b; Behling, 1992; Bove \& Barth, 1992; Barth \& Costa, 1993; Barros \& Barth, 1994; Scheel \& Barth, 1995; Garcia, 1997, 1998; Lorscheitter et al., 1998, 1999; Barros et al., 1999; Barth et al., 1997, 1998, 1999; Luz \& Barth, 1999; Barth \& Justo, 2000; Hooghiemstra, 1984; Roubik \& Moreno, 1991).

Para as análises estatísticas dos dados palinológicos foram utilizados os programas Tilia e Tilia-graph (Grimm, 1987). As análises palinológicas compreenderam também a distribuição espacial dos palinomorfos de acordo com as classes de tamanho dos palinomorfos. Para a confecção desses gráficos, foi utilizado o programa Excel, sendo considerado como significativo os percentuais acima de $6 \%$ para os palinomorfos de tamanho pequeno $(10-25 \mu \mathrm{m})$ e acima de $40 \%$ para os grãos de pólen e esporos de tamanho grande $(50-100 \mu \mathrm{m})$. 
Os palinomorfos identificados nas amostras foram agrupados de acordo com os tipos de vegetação aos quais pertencem e de acordo com a classificação de Veloso et al. (1991). Cabe destacar que, para melhor exposição dos resultados, as 27 amostras de sedimentos superficiais foram agrupadas em cinco setores espaciais, de acordo com sua localização na baía de Guanabara: (i) setor oriental da região do fundo da baía de Guanabara, onde estão localizadas a Ilha de Paquetá e a Área de Proteção Ambiental de Guapimirim, 12 amostras; (ii) setor ocidental da região do fundo da baía, acima da Ilha do Governador, três amostras; (iii) região central da baía, sete amostras; (iv) região da Ilha do Fundão, próximo ao litoral da cidade do Rio de Janeiro, três amostras; e (v) região próxima à barra de entrada da baía de Guanabara, duas amostras (Figura 1).

\section{RESULTADOS E DISCUSSÃO}

As análises palinológicas das amostras dos sedimentos superficiais da baía de Guanabara foram caracterizadas pela maior percentagem/concentração dos elementos da Vegetação Campestre (Figuras 2 e 3), destacando-se, principalmente, Poaceae, seguida de Amaranthaceae/Chenopodiaceae e Borreria (Figura 4). Em relação aos tipos polínicos da Floresta Ombrófila, a maior representatividade deveu-se a Alchornea, Arecaceae, Celtis, Hedyosmum, Meliaceae e Trema (Figura 4). Os elementos relacionados a Higrófitas (Cyperaceae e Typha) e aqueles de Ampla Distribuição (Asteraceae, Bignoniaceae, Mimosaceae e Solanaceae) (Figura 4), indicaram em grande parte a vegetação existente atualmente na bacia hidrográfica da baía de Guanabara (Araújo \& Maciel, 1979; Kurtz \& Araújo, 2000). De acordo com Veloso et al. (1991), as famílias Meliaceae e Leguminosae, além de Arecaceae e Rubiaceae, são representantes significativos na paisagem de terras baixas do Estado do Rio de Janeiro. Isso pode indicar que a "área-fonte" de grãos de pólen para essas amostras incluiu a vegetação próxima aos rios de entrada do setor oriental da baía de Guanabara, já que atualmente a cidade do Rio de Janeiro ocupa grande parte do lado ocidental da baía.

Analisando os resultados no setor oriental da região do fundo da baía de Guanabara, onde está localizada a Ilha de Paquetá e a APA de Guapimirim (amostras St08, St07, U20, U19, St15, St16, U17, St28, U16, St29, St30 e U15), a amostra U20 foi a que apresentou a maior concentração total de palinomorfos (Figura 3). A facilidade na deposição de palinomorfos nessa área deve estar associada ao nível de energia dos fluxos aquáticos mais baixos e de menor profundidade, onde a sedimentação é mais lamosa com predominância de argilas (Kjerfve et al., 1997; Amador, 1997; Catanzaro, 2002). Nessa amostra predominaram os tipos polínicos de Vegetação Campestre (principalmente Poaceae) e de Higrófitas (Pontederia, Scrophulariaceae e Typha), oriundas, possivelmente, das margens dos rios que desembocam na baía por esse setor (Araújo \& Maciel, 1979). Nas amostras U19, St 15, St 16, St 28, St 29, St30, U17, U16 e U15, localizadas nas regiões do entorno da Ilha de Paquetá, foram observados valores totais de concentração dos palinomorfos mais baixos que na amostra U20 e semelhantes entre si (Figura 3). Já nas amostras St 08 e St 07 retiradas neste setor, porém localizadas mais próximas da orla da baía, verificam-se que a queda nas concentrações de palinomorfos foi significativa (Figura 3). As baixas concentrações dos palinomorfos encontradas nessas amostras podem ser atribuídas à maior intensidade e proximidade dos influxos fluviais que por aí penetram na baía, promovendo o transporte dos palinomorfos para as áreas mais à jusante, no sentido NE-SE (em direção ao local da amostra U20). Nos resultados, as maiores concentrações de palinomorfos de tamanho grande foram observadas nas amostras St08, St07, U19, St15, St16, St28, St29, St30, todas localizadas no entorno da Ilha de Paquetá e na proximidade da orla da baía (Figura 5). Estes palinomorfos foram carreados pelos rios do setor oriental, penetraram na baía de Guanabara e foram transportados no sentido NE-SE, encontrando na diminuição da batimetria em direção à Ilha de Paquetá uma barreira natural que favoreceu sua deposição. Esse padrão foi observado também na lagoa de Cima (Luz, 2003) próximo à desembocadura dos afluentes. Outro fator importante para esta deposição diferencial é a proximidade com a vegetação existente na Ilha de Paquetá, que pode também ter servido como fonte de grãos pólen e de esporos, o que provavelmente contribuiu para o aumento desses palinomorfos nas amostras do entorno.

No setor ocidental da região do fundo da baía e Ilha do Governador (amostras U22, St23 e St24), as concentrações totais dos palinomorfos foram muito elevadas (Figura 3). Nas amostras St23 e St24 predominaram os tipos polínicos representantes da Vegetação Campestre (Poaceae, Amaranthaceae/Chenopodiaceae e Borreria) e os da Floresta Ombrófila (Alchornea, Celtis e Meliaceae) (Figura 4). Na amostra St24 constatou-se a maior concentração de Podocarpus lambertii. De acordo com Veloso et al. (1991) e Radambrasil (1983), este tipo polínico caracteriza a vegetação da Floresta Ombrófila Densa Montana. Um alto percentual de grãos de pólen deste tipo apresentou exina com danos mecânicos, o que pode estar relacionado ao transporte fluvial (Campell, 1991; Tyson, 1995).

O acúmulo de palinomorfos de tamanhos grande (50-100 $\mu \mathrm{m})$ e pequeno $(10-25 \mu \mathrm{m})$ na amostra $\mathrm{St} 24$ foi muito elevado (Figura 5), sugerindo uma área de deposição preferencial neste local. Esta preferência deveu-se, provavelmente, à proximidade com a Ilha do Governador, que serviu como um obstáculo físico (barreira) ao transporte dos grãos pelas correntes aquáticas. Já na amostra St23, somente os palinomorfos de tamanho pequeno estão mais representados, sendo a de maior valor percentual desta classe de tamanho de todas as amostras analisadas na baía (Figura 5). Essa amostra está localizada numa profundidade menor, na proximidade de um pontal existente na Ilha do Governador, o que permitiu a grande deposição dos palinomorfos de tamanho pequeno, senão, pelo contrário provavelmente teriam sido carreados para mais adiante. Resultado semelhante foi encontrado por Toledo (1998) em sedimentos superficiais na lagoa Salgada (norte fluminense) onde foi observado que, nas amostras próximas à margem norte da lagoa, ocorreu uma 


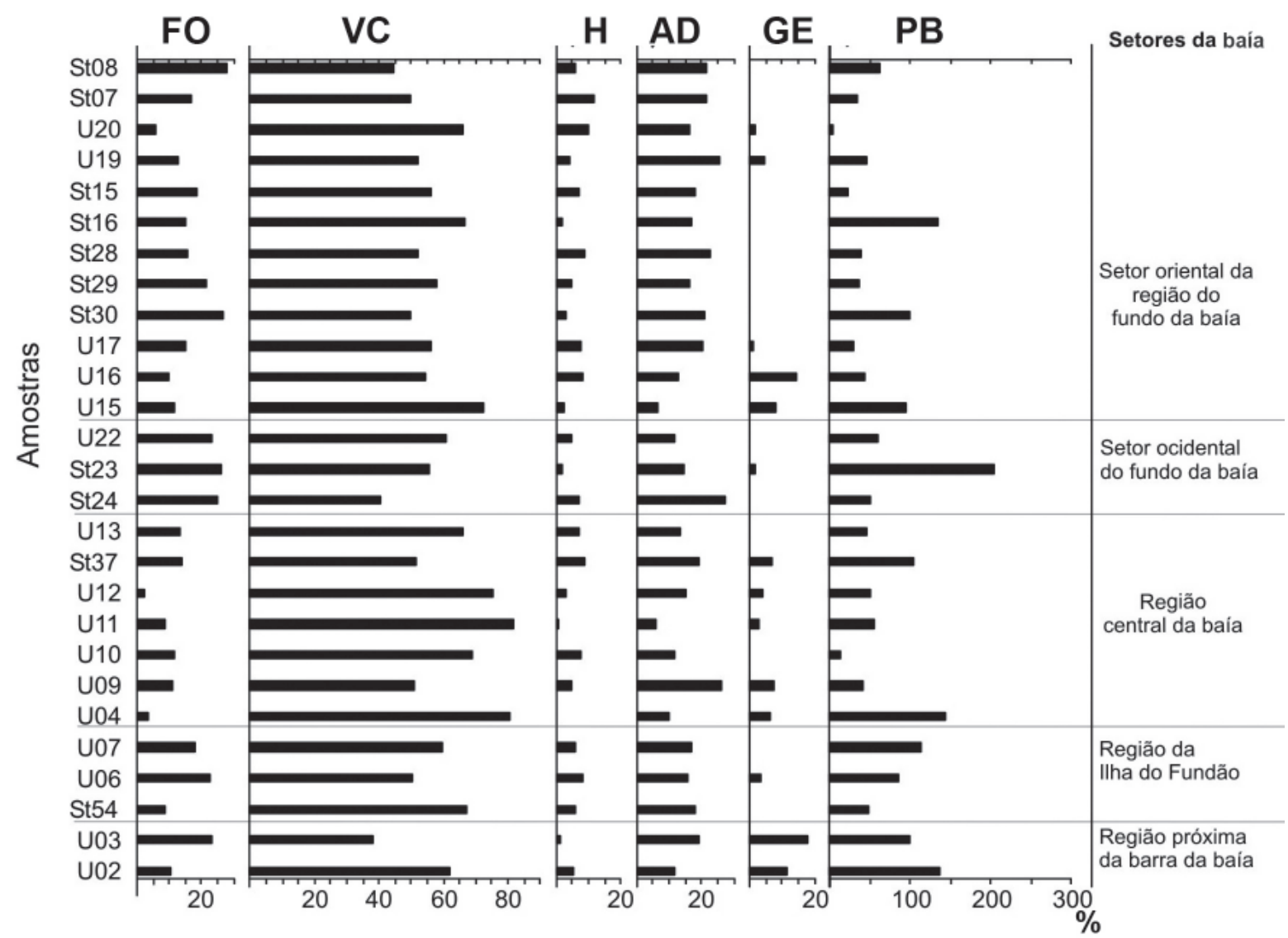

Figura 2. Palinodiagrama de percentagem dos grupos ecológicos reconhecidos nas amostras de sedimentos superficiais da baía de Guanabara. Abreviaturas: FO, Floresta ombrófila; VC, vegetação campestre; H, higrófitas; AD, ampla distribuição; GE, gêneros exóticos; PB, pteridófitas/briófitas .

Figure 2. Percentage palynodiagram of ecological groups recognized in the surface sediment samples of the Guanabara Bay. Abbreviations: FO, mixed rainforest ; VC, fields; H, higrophyllous; AD, wide distribution; GE, exotic genera; PB, pterydophytes/bryophytes

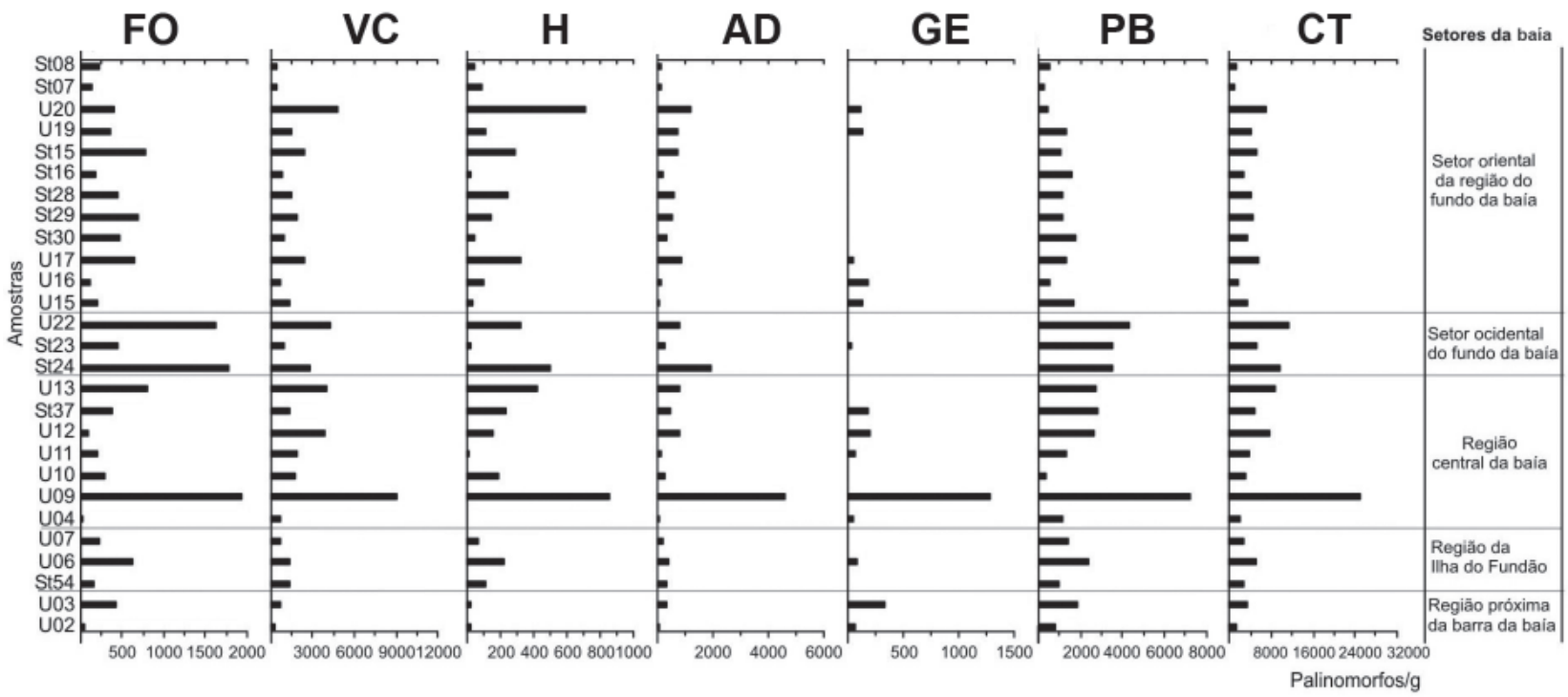

Figura 3. Palinodiagrama de concentração dos grupos ecológicos reconhecidos nas amostras de sedimentos superficiais da baía de Guanabara (escalas com valores variáveis). Abreviaturas: FO, Floresta ombrófila; VC, vegetação campestre; H, higrófitas; AD, ampla distribuição; GE, gêneros exóticos; PB, pteridófitas/briófitas, CT, concentração total.

Figure 3. Concentration palynodiagram of ecological groups recognized in the surface sediment samples of the Guanabara Bay (variable values of scales). Abbreviations: FO, mixed rainforest; VC, fields; H, higrophyllous; AD, wide distribution; GE, exotic genera; PB, pterydophytes/bryophytes; CT, total concentration. 


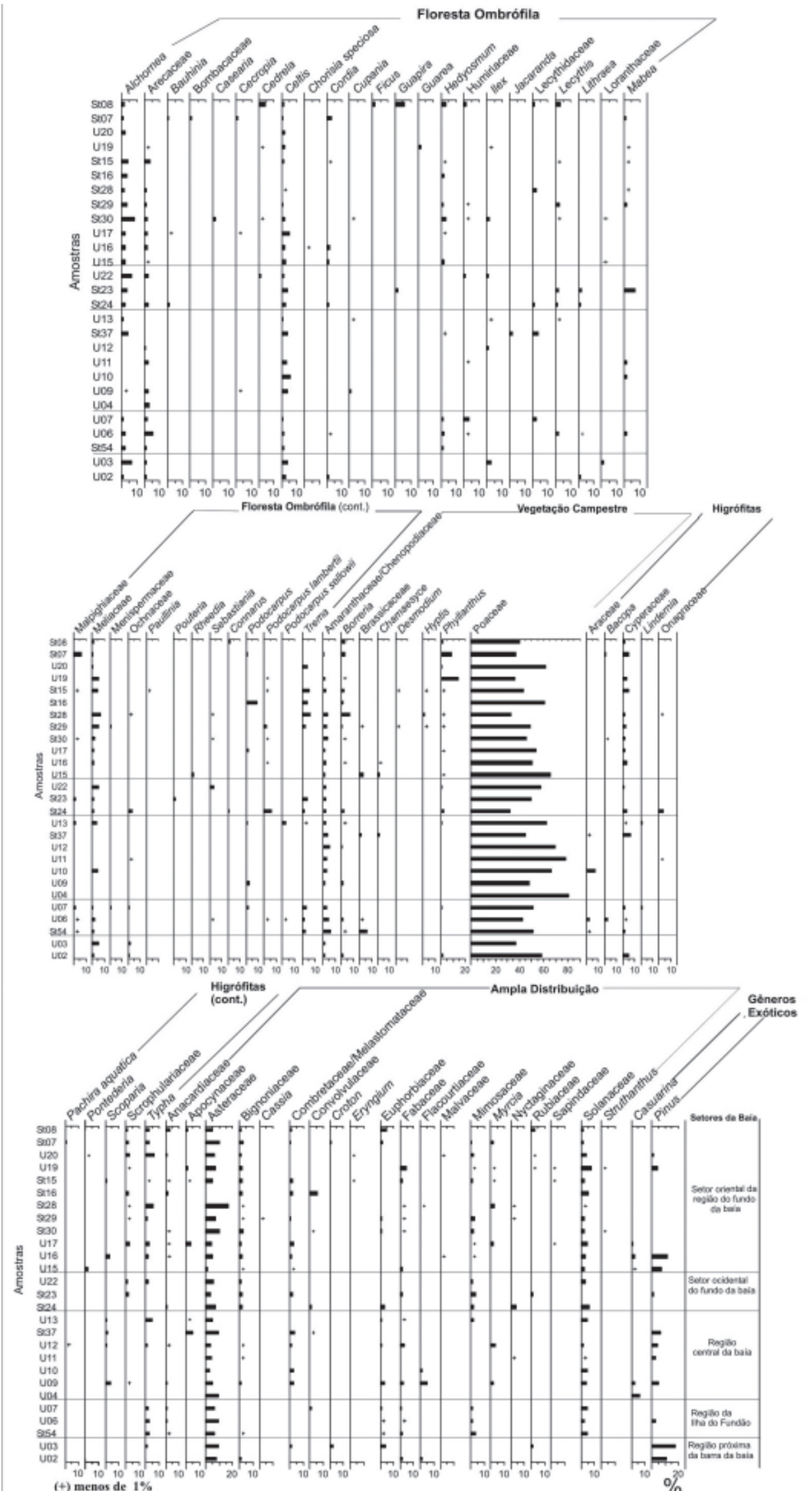

Figura 4. Palinodiagrama de percentagem dos tipos polínicos agrupados em floresta ombrófila, vegetação campestre, higrófitas, ampla distribuição e gêneros exóticos reconhecidos nas amostras de sedimentos superficiais da baía de Guanabara.

Figure 4. Percentage palynodiagram of pollen types grouped into rainforest, fields, hygrophytes, wide distribution and exotic genera recognized in the surface sediment samples of the Guanabara Bay. 
deposição de palinomorfos ligeiramente maior em comparação com as amostras próximas à margem sul. A existência de um esporão arenoso interno, na margem norte, foi o principal fator para esta deposição diferencial. A concentração total de palinomorfos na amostra U22, localizada mais ao norte neste setor e em área de menor circulação aquática, foi a mais alta das três amostras, por se localizar provavelmente em área cuja correnteza possui menor energia (Figura 3). Nessa amostra predominaram os elementos de Vegetação Campestre (Amaranthaceae/Chenopodiaceae, Phyllanthus e Poaceae) e da Floresta Ombrófila (Alchornea, Arecaceae, Meliaceae e Sebastiania) (Figura 4), não apresentando um predomínio de palinomorfos em relação à classe de tamanho.

Já no setor central da baía (amostras U13, U12, St37, U11, U10, U09 e U04), as concentrações totais de palinomorfos variaram muito entre as amostras (Figura 3). Dentre estas, a amostra U09 foi a que apresentou a concentração mais alta de todas, predominando os palinomorfos pequenos. Nas amostras U11, U10 e U04, os valores de concentração foram mais baixos. Já nas amostras U12, U13 e St 37, as concentrações dos palinomorfos apresentaram valores elevados com predomínio de tipos polínicos representantes de Vegetação Campestre (Poaceae, Amaranthaceae/ Chenopodiaceae e Borreria), Floresta Ombrófila (Alchornea e Celtis), Higrófitas (Scoparia e Typha) e Ampla Distribuição (Asteraceae e Solanaceae) (Figura 4). A localização da amostra St 37, por estar próxima à orla leste da Ilha do Governador, propiciou a deposição de palinomorfos pequenos que, por sua baixa densidade, foram carreados pela correnteza do canal central para o interior da baía de Guanabara. Na amostra U09 predominaram os tipos polínicos de Vegetação Campestre (Amaranthaceae/Chenopodiaceae, Borreria e Poaceae), Floresta Ombrófila (Alchornea, Arecaceae, Cecropia, Celtis, Cupania), Higrófitas (Scoparia), Ampla Distribuição (Anacardiaceae, Asteraceae, Bignoniaceae, Combretaceae/ Melastomataceae, Euphorbiaceae, Fabaceae, Flacourtiaceae, Myrcia e Solanaceae) e Espécies Exóticas (Casuarina e Pinus) (Figura 4). A amostra U09, localizada na área de passagem à frente da barra de entrada da baía, apresenta diminuição da profundidade e provavelmente serve como barreira ao carreamento dos palinomorfos remobilizados dos sedimentos do interior da baía. Nas amostras U04, U10 e U11, os tipos polínicos predominantes se relacionaram aos de Vegetação Campestre (Amaranthaceae/Chenopodiaceae e Poaceae) e Floresta Ombrófila (Alchornea, Arecaceae e Meliaceae) (Figura 4). Analisando os resultados nesse setor, a baixa concentração ocorreu nas amostras U04, U10 e U11, ao contrário das U12, U13, St 37 e U09, o que indica que mesmo em áreas de alta energia a menor batimetria tem grande influência na deposição dos palinomorfos.

No setor da região da Ilha do Fundão e próximo à Praça XV (amostras U07, U06 e St54), as concentrações totais de palinomorfos apresentaram baixos valores (Figura 3). Na amostra U06 predominaram os representantes da Vegetação Campestre (Amaranthaceae/Chenopodiaceae, Borreria e Poaceae), além daqueles da Floresta Ombrófila (Alchornea, Arecaceae e Meliaceae) e Higrófitas (Araceae e Typha) (Figura 4).
Os maiores percentuais de palinomorfos de tamanho grande e a maior riqueza de tipos polínicos encontrada nas amostras U06 e U07 evidenciam uma região preferencial de deposição, devido principalmente à baixa energia das correntes nesses locais. Segundo Amador (1997), o estreitamento geomorfológico a noroeste da Ilha do Governador favorece o aumento na velocidade das correntes de maré, mesmo tratando-se de uma região dominada por baixa energia. Este fator possivelmente promoveu a remobilização de palinomorfos previamente depositados em outras áreas para esse setor, já que o local é totalmente urbanizado e não apresenta "área fonte" próxima. Os palinomorfos de tamanho pequeno predominaram na amostra St54 (Figura 5), já que essa região é a mais calma e protegida da correnteza.

Já no setor próximo da barra de entrada da baía de Guanabara (amostras U03 e U02), as concentrações totais dos palinomorfos foram muito baixas (Figura 3). Os tipos polínicos de Floresta Ombrófila (Alchornea, Arecaceae, Celtis, Meliaceae, Ochnaceae), Vegetação Campestre (Poaceae), Ampla Distribuição (Asteraceae), Espécies Exóticas (Pinus) foram os tipos polínicos que ocorreram nas duas amostras, com o predomínio da família Poaceae (Figura 4). A baixa deposição dos palinomorfos nessas amostras pode estar associada à alta energia no local, que poderia favorecer o carreamento dos palinomorfos para regiões mais internas da baía no sentido S-N (de acordo com a correnteza do canal principal). Segundo Kjerfve et al. (1997), o estreitamento morfológico nas proximidades da barra de entrada da baía de Guanabara provoca um aumento considerável nas velocidades das correntes de maré, com os maiores valores ocorrendo na margem leste (próximo ao Forte de Gragoatá) e próximo ao Aeroporto Santos Dumont, coincidindo com o ponto de retirada das amostras.

\section{CONCLUSÕES}

As análises palinológicas das amostras dos sedimentos superficiais da baía de Guanabara foram caracterizadas pelos maiores valores de concentração dos elementos da Vegetação Campestre e grande riqueza de tipos polínicos da Floresta Ombrófila das terras baixas, refletindo a vegetação regional existente atualmente na bacia hidrográfica da baía de Guanabara.

Em geral, a distribuição diferencial dos palinomorfos nos sedimentos superficiais da baía de Guanabara seguiu um padrão influenciado pela batimetria, associada principalmente ao padrão de correntes gerado pelas marés, os quais, em conjunto, promoveram a concentração dos palinomorfos nas áreas mais profundas (próximas ao canal principal) e em locais onde a circulação da água encontrava um obstáculo topográfico (por exemplo, as ilha de Paquetá e Governador). A deposição diferencial em relação ao tamanho dos palinomorfos seguiu um padrão geral de acumulação de palinomorfos de tamanho pequeno nas áreas de maior correnteza e os de tamanho grande em áreas de menor batimetria (próximo às áreas protegidas das ilhas e na desembocadura dos rios do setor oriental).

No setor oriental da região de fundo da baía, os influxos 


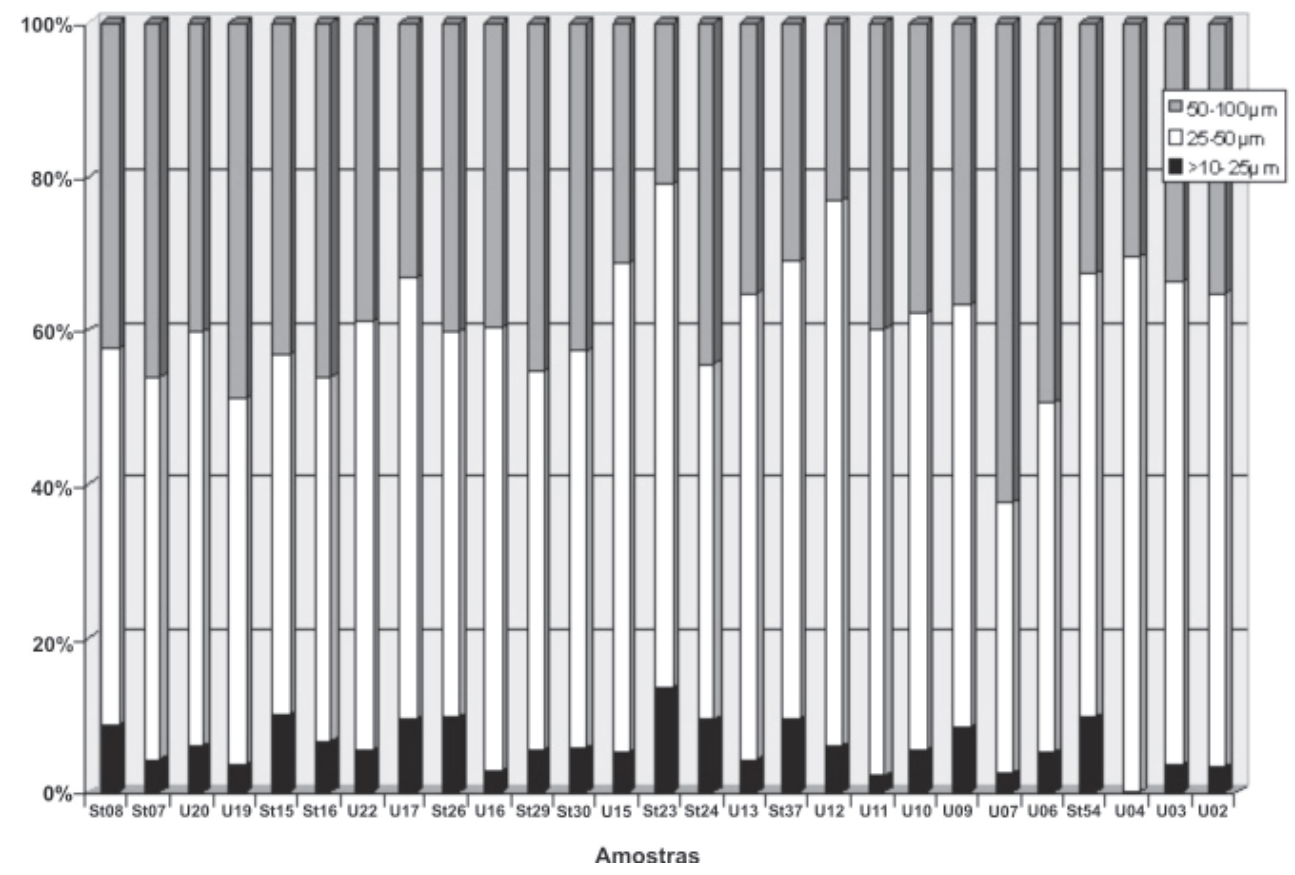

Figura 5. Percentagem de classes de tamanho de grãos de pólen e esporos nas amostras de sedimentos superficiais da baía de Guanabara.

Figure 5. Percentage classes of pollen grain and spore sizes in the surface sediment samples of the Guanabara Bay.

dos rios de entrada e a batimetria (principalmente a existência da Ilha de Paquetá) foram os fatores determinantes para o aumento na deposição dos palinomorfos. No setor ocidental da região de fundo da baía e na Ilha do Governador, as concentrações totais foram as mais elevadas de todas as amostras analisadas. A existência da Ilha do Governador com seus pontais serviram como barreiras naturais ao fluxo aquático, ocasionando o aumento das concentrações dos palinomorfos nesses sedimentos superficiais. Já o setor central da baía é uma área de passagem de correntes de alta energia. A menor profundidade de algumas amostras foi o fator que propiciou a maior deposição de palinomorfos neste setor. A primeira amostra de menor profundidade contígua à barra de entrada foi a que apresentou a maior concentração de todas as amostras de superfície analisadas. Essa amostra (U09) possivelmente vem recebendo os palinomorfos remobilizados dos sedimentos superficiais pelas correntes internas. O setor da região da Ilha do Fundão apresenta um padrão de correntes complexo, devido à morfologia de sua costa, que forma um bolsão próprio para a deposição de palinomorfos de tamanho grande, provavelmente remobilizados de outras áreas da baía. No setor próximo da barra de entrada da baía, as baixas concentrações totais dos palinomorfos foram associadas à alta energia das correntezas no local, que estariam provocando o seu carreamento para dentro da baía. Estes padrões deposicionais de palinomorfos na baía de Guanabara devem ser considerados para estudos que envolvam Palinologia do Quaternário baseados em análises de testemunhos de sondagem.

\section{AGRADECIMENTOS}

Os autores agradecem a Beatriz Beck Eichler e José Antônio Baptista Neto, por terem fornecido as amostras utilizadas neste trabalho; a Wolfram Brenner, pela realização da primeira etapa de preparação química do material, e ao CNPq e à CAPES, pelo suporte financeiro.

\section{REFERÊNCIAS}

Amador, E.S. 1997. Baía de Guanabara e ecossistemas periféricos: homem e natureza. Rio de Janeiro, Edição do Autor, 539 p.

Araújo, D.S.D. \& Maciel, N.C. 1979. Os manguezais do recôncavo da baía de Guanabara. Rio de Janeiro, Cadernos da Fundação Estadual de Engenharia do Meio Ambiente (FEEMA), Divisão de Comunicação e Treinamento, 60 p. (Série Técnica 10/79).

Barreto, C.F.; Barth, O.M.; Brenner, W.; Morgado, L.N. \& Vilela, C.G. 2003. Análises palinológicas de sedimentos da superfície de depósitos do fundo da baía de Guanabara, Rio de Janeiro, Brasil. In: CONGRESSO DA ASSOCIAÇÃO BRASILEIRA DE ESTUDOS DO QUATERNÁRIO, 9, 2003. Recife, CD-ROM.

Barros, M.A. \& Barth, O.M. 1994. Catálogo sistemático do pólen das plantas arbóreas do Brasil Meridional - XXVIII. Burseraceae e Clethraceae. Revista Brasileira de Biologia, 54(2):317-322.

Barros, M.A.; Barth, O.M. \& Costa, K.M.R. 1999. Catálogo sistemático dos pólens das plantas arbóreas do Brasil Meridional. XXXII - Família Anacardiaceae. Leandra, 14:17-24.

Barth, O.M. 1962a. Catálogo sistemático dos pólens das plantas arbóreas do Brasil Meridional - Parte Complementar: Coniferales. Memórias do Instituto Oswaldo Cruz, 60(2):199-208.

Barth, O.M. 1962b. Catálogo sistemático dos pólens das plantas arbóreas do Brasil Meridional - II. Monimiaceae e Dilleniaceae. 
Memórias do Instituto Oswaldo Cruz, 60(3):405-420.

Barth, O.M. 1963. Catálogo sistemático dos pólens das plantas arbóreas do Brasil Meridional - III. Theaceae, Marcgraviaceae, Ochnaceae, Guttiferae e Quiinaceae. Memórias do Instituto Oswaldo Cruz, 61(1):89-110.

Barth, O.M. 1964. Catálogo sistemático dos pólens das plantas arbóreas do Brasil Meridional - V. Leguminosae: Papilionatae. Memórias do Instituto Oswaldo Cruz, 62:95-123.

Barth, O.M. 1971a. Catálogo sistemático dos pólens das plantas arbóreas do Brasil Meridional - IX. Complemento à parte VII: Cuphea (Lythraceae). Memórias do Instituto Oswaldo Cruz, 69(1):93-105.

Barth, O.M. 1971b. Catálogo sistemático dos pólens das plantas arbóreas do Brasil Meridional - X. Proteaceae. Memórias do Instituto Oswaldo Cruz, 69(3):437-447.

Barth, O.M. 1972a. Catálogo sistemático dos pólens das plantas arbóreas do Brasil Meridional - XIII. Flacourtiaceae e Caricaceae. Memórias do Instituto Oswaldo Cruz, 70(1):1-13.

Barth, O.M. 1972b. Catálogo sistemático dos pólens das plantas arbóreas do Brasil Meridional - XI. Loranthaceae e Olacaceae. Memórias do Instituto Oswaldo Cruz, 70(1):49-67.

Barth, O.M. 1975. Catálogo sistemático dos pólens das plantas arbóreas do Brasil Meridional - XVIII. Malvaceae. Memórias do Instituto Oswaldo Cruz, 73(1-2):1-30.

Barth, O.M. 1976a. Catálogo sistemático dos pólens das plantas arbóreas do Brasil Meridional - XXIII. Moraceae. Memórias do Instituto Oswaldo Cruz, 74(3-4):295-309.

Barth, O.M. 1976b. Catálogo sistemático dos pólens das plantas arbóreas do Brasil Meridional - XXIV. Urticaceae. Memórias do Instituto Oswaldo Cruz, 74(3-4):341-346.

Barth, O.M. \& Barbosa, A.F. 1971. Catálogo sistemático dos pólens das plantas arbóreas do Brasil Meridional - XII. Palmae. Memórias do Instituto Oswaldo Cruz, 69(3):425-433.

Barth, O.M. \& Barbosa, A.F. 1972a. Catálogo sistemático dos pólens das plantas arbóreas do Brasil Meridional - XIV. Nyctaginaceae e Phytolaccaceae. Memórias do Instituto Oswaldo Cruz, 70(3):241-267.

Barth, O.M. \& Barbosa, A.F. 1972b. Catálogo sistemático dos pólens das plantas arbóreas do Brasil Meridional - XV. Myrtaceae. Memórias do Instituto Oswaldo Cruz, 70(4):467-498.

Barth, O.M. \& Barbosa, A.F. 1972c. Catálogo sistemático dos pólens das plantas arbóreas do Brasil Meridional - XVI. Ericaceae. Memórias do Instituto Oswaldo Cruz, 70(4):555-575.

Barth, O.M. \& Barbosa, A.F. 1973. Catálogo sistemático dos pólens das plantas arbóreas do Brasil Meridional - XVII. Elaeocarpaceae e Tiliaceae. Memórias do Instituto Oswaldo Cruz, 71(3):203-217.

Barth, O.M. \& Barbosa, A.F. 1975a. Catálogo sistemático dos pólens das plantas arbóreas do Brasil Meridional - XIX. Melastomataaceae. Memórias do Instituto Oswaldo Cruz, 73(12):39-60.

Barth, O.M. \& Barbosa, A.F. 1975b. Catálogo sistemático dos pólens das plantas arbóreas do Brasil Meridional - XX. Chloranthaceae e Piperaceae. Memórias do Instituto Oswaldo Cruz, 73(1-2):101-108.

Barth, O.M. \& Barbosa, A.F. 1976a. Catálogo sistemático dos pólens das plantas arbóreas do Brasil Meridional - XXI. Canellaceae. Memórias do Instituto Oswaldo Cruz, 74(2):147-152.

Barth, O.M. \& Barbosa, A.F. 1976b. Catálogo sistemático dos pólens das plantas arbóreas do Brasil Meridional - XXII. Linaceae-Humirioideae e Erythroxylaceae. Memórias do Instituto Oswaldo Cruz, 74(3-4):203-212.
Barth, O.M.; Barreto, C.F.; Coelho, L.G. \& Luz, C.F.P. 2004. Pollen record and paleoenvironment of a 4210 years B.P. old sediment in the Bay of Guanabara, Rio de Janeiro, Brazil. Anais da Academia Brasileira de Ciências, 76(3):549-551.

Barth, O.M. \& Bouzada, C.P. 1964. Catálogo sistemático dos pólens das plantas arbóreas do Brasil Meridional - VI. Leguminosae: Caesalpinioideae. Memórias do Instituto Oswaldo Cruz, 62:169-192.

Barth, O.M. \& Costa, K.M.R. 1993. Catálogo sistemático do pólen das plantas arbóreas do Brasil Meridional - XXVI. Aquifoliaceae. Revista Brasileira de Biologia, 53(2):305-309.

Barth, O.M. \& Justo, R.L. 2000. Catálogo sistemático dos pólens das plantas arbóreas do Brasil Meridional-XXXIV. Sapotaceae. Leandra, 15:35-45.

Barth, O.M.; Leite, G.M. \& Bove, C.P. 1997. Catálogo sistemático de pólen das plantas arbóreas do Brasil Meridional. XXXI: Rhamnaceae. Leandra, 12:45-53.

Barth, O.M. \& Silva, S.A.F. 1963. Catálogo sistemático dos pólens das plantas arbóreas do Brasil Meridional - IV. Cunoniaceae, Rosaceae e Connaraceae. Memórias do Instituto Oswaldo Cruz, 61(3):411-433.

Barth, O.M. \& Silva, S.A.F. 1965. Catálogo sistemático dos pólens das plantas arbóreas do Brasil Meridional - VII. Thymelaeaceae, Lythraceae, Lecythidaceae, Rhizophoraceae e Combretaceae. Memórias do Instituto Oswaldo Cruz, 63:255-273.

Barth, O.M. \& Yoneshigue, Y. 1966. Catálogo sistemático dos pólens das plantas arbóreas do Brasil Meridional - VII. Leguminosae: Mimosoideae. Memórias do Instituto Oswaldo Cruz, 64:79-111.

Behling, H. 1992. Untersuchungen zur Spätpleistozänen und Holozänen Vegetations und Klimageschichte der Tropischen Küstenwälder und der Araukarienwälder in Santa Catarina (Südbrasilien). Mathematisch - Naturwissenschaftliche Fachbereiche der Georg-August Universität, Tese de Doutorado, 149 p.

Bove, C.P. \& Barth, O.M. 1992. Catálogo sistemático do pólen das plantas arbóreas do Brasil Meridional - XXV. Bignoniaceae. Revista Brasileira de Biologia, 52(2):283-292.

Brenner, W.W. 1998. Grundlagenundan-wendungsmöglichkeiten der mikro-Absorptionsphtometrie für organischwandige Mikrofossilien. GEOMAR, Research Center for Marine Geosciences, Christian Albrechts University, Kiel. Geomar Report, 76:38-106.

Catanzaro, L.F. 2002. Distribuição de sedimentos e características de ecocarater $(7,0 \mathrm{kHz})$ na baía de Guanabara, RJ-Brasil. Programa de Pós-graduação em Geologia, Universidade Federal Fluminense, Dissertação de Mestrado, 58 p.

Davis, M.B. \& Brubaker, L.B. 1973. Differential sedimentation of pollen grains in lakes. Limnology and Oceanography, 18(4):635-646.

Dias, G.T.M. \& Quaresma,V.S. 1996. Baía de Guanabara - Evolução geomorfológica do fundo submarino. In: CONGRESSO BRASILEIRO DE GEOLOGIA, 34, 1996. Anais, Salvador, 4:514-517.

Garcia, M.J. 1997. Palinologia de turfeiras quaternárias do médio vale do rio Paaiba do Sul, Estado de São Paulo, Brasil. Parte 1: Fungos, Algas, Bryophyta e Pteridophyta. Revista Universidade de Guarulhos, Geociências, 2(número especial):148-165.

Garcia, M.J. 1998. Palinologia de turfeiras quaternárias do médio vale do rio Paraíba do Sul, Estado de São Paulo, Brasil. Parte 2: gymnospermae e magnoliophyta. Revista Universidade de Guarulhos, Geociências, 3(6):148-165. 
Grimm, E.C. 1987. Coniss: A Fortran 77 program for stratigraphically constrained cluster analisys by the method of the incremental sum of squares. Pergamon Journals, 13:13-35.

Hooghiemstra, H. 1984. Vegetacional and climatic history of the high plain of Bogotá, Colombia: a continuous record of the last 3.5 million years. CRAMER, J. (ed.) Dissertationes Botanicae, $367 \mathrm{p}$.

Kjerfve, B.; Ribeiro, C.H.; Dias, G.T.M.; Filippo, M.\& Quaresma,V.S. 1997. Oceanographic characteristics of an impacted coastal bay: baía de Guanabara, Rio de Janeiro, Brazil. Continental Shelf Research, 17(13):1609-1643.

Kurtz, B.C. \& Araújo, D.S.D. de 2000. Composição florística e estrutura do componente arbóreo de um trecho de Mata Atlântica na Estação Ecológica Estadual do Paraíso, Cachoeiras de Macacu, Rio de Janeiro, Brasil. Rodriguésia, 51(78/115):69-112.

Lorscheitter, M.L.; Ashraf, A.R.; Bueno, R.M. \& Mosbrugger, V. 1998. Pteridophyte spores of Rio Grande do Sul flora, Brazil, Part I. Palaeontographica, Abt. B 246(1-3):1-113.

Lorscheitter, M.L.; Ashraf, A.R.; Windisch, P.G. \& Mosbrugger, V. 1999. Pteridophyte spores of Rio Grande do Sul flora, Brazil, Part II. Palaeontographica, Abt. B 251(4-6):71-235.

Luz, C.F.P. 2003. Os registros palinológicos como sensores das dinâmicas da vegetação no Holoceno da região norte do Estado do Rio de Janeiro (Brasil). Programa de Pós-graduação em Geologia, Universidade Federal do Rio de Janeiro, Tese de Doutorado, $168 \mathrm{p}$.

Luz, C.F.P. \& Barth, O.M. 1999. Catálogo sistemático dos pólens das plantas arbóreas do Brasil Meridional. XXXIII. Sapindaceae. Leandra, 14:25-36.

Quaresma, V.S. 1997. Caracterização da dinâmica sedimentar da baía de Guanabara, RJ. Programa de Pós-graduação em Geologia, Universidade Federal Fluminense, Dissertação de Mestrado, $97 \mathrm{p}$.

Radambrasil, 1983. Folhas SF. 23/24, Rio de Janeiro/Vitória; geologia, geomorfologia, pedologia, vegetação e uso potencial da terra. Rio de Janeiro, MME (sec. ger.), v. 32, 780 p.

Roubik, D.W. \& Moreno, J.E.P. 1991. Pollen and spores of Barro Colorado Island. Monographs in Systematics Botany from the Missouri Botanical Garden, v. 36, 270 p.

Scheel, R. \& Barth, O.M. 1995. Catálogo sistemático do pólen das plantas arbóreas do Brasil Meridional - XXIX. Boraginaceae. Revista Brasileira de Biologia, 55(4):769-776.

Stockmarr, J. 1971. Tablets with espores used in absolute pollen analysis. Pollen et Spores, 13:615-621.

Toledo, M.B. 1998. Evolução Ambiental da lagoa Salgada, Sudeste do Brasil, com base em estudos palinológicos. Programa de Pós-graduação em Geologia e Geofísica Marinha, Universidade Federal Fluminense, Dissertação de Mestrado, 29 p.

Traverse, A. 1994. Sedimentation of organic particles. New York, Syndicate of the University the of Cambridge, $524 \mathrm{p}$.

Tyson, R.V. 1995. Sedimentary organic matter. Londres, Chapman \& Hall, 614 p.

Veloso, H.P. \& Barth, O.M. 1962. Catálogo sistemático dos pólens das plantas arbóreas do Brasil Meridional - I. Magnoliaceae, Annonaceae, Lauraceae e Myristicaceae. Memórias do Instituto Oswaldo Cruz, 60(1):59-93.

Veloso, H.P.; Rangel Filho, L.R. \& Lima, J.C.A 1991. Classificação da vegetação brasileira adaptada a um sistema universal. Rio de Janeiro. Instituto Brasileiro de Geografia (IBGE), 124 p.

Vilela, C.G.; Baptista Neto, J.A.; Mendonça Filho, J.G.; Sanjinés, A.E.; Batista, D.S. \& Barbosa, C.F. 2002. Benthic foraminifera occurrence in subenvironments on Guanabara Bay, Rio de Janeiro, southeast Brasil. In: INTERNATIONAL SYMPOSIUM PERTH ON FORAMINEFERA WESTERN AUSTRALIA, FORAMS, 2002. Abstracts, Perth, p. 70.

Ybert, J.-P.; Salgado-Labouriau, M.L.; Barth, O.M.; Lorscheitter, M.L.; Barros, M.A.; Chaves, S.A.M.; Luz, C.F.P.; Ribeiro, M.; Scheel, R. \& Vicentini, K.R.F. 1992. Sugestões para padronização da metodologia empregada para estudos palinológicos do Quaternário. Revista do Instituto Geológico, 13(2):47-49.

Received in January, 2006; accepted in March, 2006. 